EDITORIAL

\title{
Passion, Action, and Reflection
}

\author{
Brynjulf Stige $^{1 *}$, Susan Hadley ${ }^{2}$, Katrina McFerran ${ }^{3}$ \\ 1 University of Bergen, Norway \\ 2 Slippery Rock University, USA \\ 3 University of Melbourne, Australia \\ *brynjulf.stige@uib.no
}

Published: 1 July 2019

This issue of Voices contains an intriguing range of articles, about the humanizing potential of music therapy in end of life care (Zoe Tao), sequential working memory recall in neurodivergent and neurotypical individuals (Edward Todd Schwartzberg \& Michael $\mathrm{J}$ Silverman), the role of music listening in vibroacoustic treatment (Elsa Campbell, Birgitta Burger \& Esa Ala-Ruona), the therapeutic value of recording in music therapy (Kevin Kirkland \& Shannon Nesbitt), and proposed mechanisms of change in the arts-based psychotherapies (Anna Gerge, Jane Hawes, Lotti Eklöf \& Inge Nygaard Pedersen). There is also a review of Elizabeth Schwartz, Sharon R. Boyle and Rebecca Engen'sFunctional Voice Skills for Music Therapists (Sylka Uhlig) and - last but not least - there is a beautiful tribute to the life and work of Benedikte Scheiby (Seung-A Kim \& Kenneth Aigen). These contributions clearly reflect the work of practitioners and researchers with a passion for music and the relationships and changes that can grow out of music therapy.

In this editorial, we also want to communicate our respect for the many collaborators that make a forum like Voices possible, and, also, their capacity to act and reflect! One person who deserves particular attention at this point is Rune Rolvsjord, who after 20 years of dedication is leaving his position as our Managing Editor and is starting a new adventure as the web editor of NORCE Norwegian Research Centre. While this is very sad for us, it is a wonderful opportunity for him.

When the first dialogues about the possibility of an international Open Access journal in music therapy started at the World Congress in Washington in 1999, Rune was there. When the new forum - which we had given the name Voices - was launched during the European Music Therapy Conference in Naples in 2001, Rune was there. In between those dates, and ever since, Rune responded to countless questions about small and large issues, and countless technical and logistic challenges were solved. Through words, images, videos and design, Voices has evolved as an inclusive forum for dialogue and debate, and Rune's capacity and willingness to be part of this process has been invaluable. We want to take the opportunity to share our deep, long-standing respect for Rune Rolvsjord's contribution, for his kindness, his cleverness, and his knowledge. Thank you so much and best wishes Rune!

We also want to take the opportunity to welcome our new Managing Editor, Hilde Kjerland, who - together with the rest of the editorial team - has done a fantastic job in preparing this issue. 
Finally, we take the opportunity to welcome the new Voices moderators Maren Metell and Lucy Bolger. When you visit our website, you will notice a new "button" in the main menu: "Global Voices Wiki". We are proud to introduce "Global Voices of Music Therapy: An interactive wiki" as a new platform for music therapists from around the world to share information about the practice and development of music therapy in their country. Information for individual country wiki pages will be generated and edited by users themselves, using the common framework of sub headings provided. Our hope is that this will be an inclusive and respectful forum, and multiple perspectives are encouraged. We invite you all to take part in continued sharing of information, as a basis for dialogues and debates about the things we should be passionate about in music therapy. 